\title{
Fatty Acids Profile, Oxidative and Hydrolysis Stability of Virgin Coconut Oil and Palm Stearin Based Human Milk Fat Analog
}

\author{
Steivie Karouw ${ }^{1}$, Suparmo ${ }^{2}$, Pudji Hastuti ${ }^{2}$, and Tyas Utami ${ }^{2}$
}

\begin{abstract}
The objectives of the research are to evaluate fatty acids profile, oxidative and hydrolysis stability of human milk fat (HMF) analog by using virgin coconut oil (VCO) and palm stearin as raw materials. The HMF analog was synthesized through enzymatic interesterification catalyzed by lipase from Rhizoтисо miehei. The fatty acid profiles of interesterification products were monitored using gas chromatography. Oxidative stability test was carried out for up to 72 hours at $60^{\circ} \mathrm{C}$. The peroxide value was measured during 0, 24, 48 and 72 hours of storage duration. Hydrolysis stability test was held for up to 8 days at room temperature. The free fatty acid content was monitored during $0,2,4,6$ and 8 days of storage. The results showed that the resulted HMF analog having high percentage of palmitic acid in the sn-2 position, similar to that of HMF. The palmitic acid content in the sn-2 position was around $39.71 \%$. The MCFAs were esterified in the sn- 1 and sn-3 position and the main fatty acid constituent was lauric acid of $39.37 \%$. The obtained HMF analog was stable to oxidative and hydrolysis deterioration as indicated by the peroxide value and free fatty acid content during storage.
\end{abstract}

Keywords: interesterification, gas chromatography, peroxide value, lauric acid, palmitic acid

\footnotetext{
${ }^{1}$ Indonesian Palmae Research Institute, Manado-95001, North Sulawesi, Indonesia. Email: steivie_karouw@yahoo.com

${ }^{2}$ Department of Food Science and Technology, Faculty of Agricultural Technology, University of Gadjah Mada, Bulaksumur, Yogyakarta, Indonesia.
} 


\section{Introduction}

Human milk is considered to be the best food for infants in their daily lives However, for some reasons many mothers have to depend on infant milk formulae to feed their babies. Positional distribution of acyl groups bonded to the glycerol is significant differences between human milk fat (HMF) and infant milk fat formulae. HMF has the high percentage of palmitic acid (18.62-23.02\%). Palmitic acid in HMF was predominantly located in the sn-2 position of the triglycerides (Yuhas et al., 2006), meanwhile infant formulae contained palmitic acid predominantly in sn-1,3 positions (Schmid et al., 1998). The role of palmitic acid in the sn2 position of the glycerol backbone is to ease the digestion and absorption of the fats in the infant intestine. Long chain saturated fatty acids (LCFAs), like palmitic acid, esterified to sn-1,3 positions during the digestion, can form insoluble fatty acid complexes with calcium, rendering it unavailable (Carnielli et al., 1995).

Lauric acid, as a member of medium chain fatty acids (MCFAs), which in the virgin coconut oil (VCO), amounted 46.64-48.03\% (Marina et al., 2009). Lauric acid was found to increase body endogenous oxidation by changing the composition of the adipose tissue pool through altered endogenous availability. The capability of medium chain triglyceride (MCTs) to increase endogenous fat oxidation could have implications in the reduction of adipose tissue mass by increasing adipose tissue mobilization (Binnert, et al., 1998; Papamandjaris, et al., 2000).

Recently, much attention has been given to the preparation of HMF analog. To our knowledge, in the literature, no research was conducted regarding the synthesis of HMF analog from palm stearin and coconut oil. In the present work, we studied synthesis of HMF analog to evaluate fatty acid profile, oxidative and hydrolysis stability of HMF analog by using VCO and palm stearin as raw materials.

\section{Materials and methods}

\section{Materials}

Palm stearin was purchased from a local palm oil plant in Bitung, North Sulawesi, Indonesia. VCO was extracted from fruit of Mapanget Tall coconut variety (11-12 months old) which was obtained from Kima Atas experimental garden in Manado. An immobilized lipozyme RM IM from Rhizomucor miehei, porcine pancreatic lipase type II, and lipid standards such as trilaurin, lauric acid, and 1,3 dipalmitin were purchased from Sigma, Netherland. Standard 2-monopalmitin was obtained from Larodan, Sweden. Silica gel F254 plates $(20 \times 20 \mathrm{~cm})$ was purchased from Merck, Germany. All solvents were of analytical grade and were purchased from Merck, Germany.

\section{Preparation of fatty acid methyl ester from coconut oil}

Potassium metoxide solution was prepared by dissolving $4.2 \mathrm{~g}$ of potassium hydroxide in 97 $\mathrm{ml}$ of methanol. This solution was added into $300 \mathrm{~g}$ of VCO in $500 \mathrm{ml}$ glass round vessel equipped with condensor and a thermometer. Methanolysis reaction was carried out at $50^{\circ} \mathrm{C}$ for 2 hours on a hot plate. The reaction products were then transferred into a separating funnel and allowed to separate for 2 hours. The upper layer, which is fatty acid methyl ester, was separated from the remaining glycerol in the lower layer. The fatty acid methyl ester was transferred into a clean separating funnel and washed 3 times with $500 \mathrm{ml}$ of water while the glycerol was discarded. The fatty acid methyl ester layer was then passed through anhydrous sodium sulfate $3 \%(\mathrm{w} / \mathrm{v}$, of fatty acid methyl ester) to remove any residual water. The fatty acids profile were then determined by gas chromatography.

\section{Hydrolysis of palm stearin to obtain high palmitate 2-monoglyceride}

High palmitate 2-monoglyceride was obtained by hydrolysis of palm stearin at temperature of $37^{\circ} \mathrm{C}$ for 42 hours in 80 stroke/minute waterbath shaker. The condition was optimized in our previous study (Karouw et al., 2013). The process was conducted as follow: 
A reaction mixture was prepared consisted of $2 \mathrm{~g}$ palm stearin, $8 \mathrm{ml}$ isooctane, and $800 \mathrm{ml}$ phospate buffer $\mathrm{pH}$ 6.5. Porcine pancreatic lipase Type II was added into the reaction mixture. The amount of porcine pancreatic lipase was 5\% $(\mathrm{w} / \mathrm{w})$ of weight of palm stearin in the reaction mixture. Enzymatic hydrolysis reaction was carried out at temperature of $37^{\circ} \mathrm{C}$ for 42 hours in a waterbath shaker with speed of 80 strokes/minute. At the end of the reaction lipase was separated from reaction mixture by centrifugation, and the solvents were removed under a stream of $\mathrm{N}_{2}$ gas. Leave reaction products at the bottom of the flask.

\section{Separation of 2-monoglyceride}

The 2-monoglyceride was isolated from the reaction products by TLC. The reaction products were dissolved in chloroform and then applied to TLC plates, developed in petroleum ether: diethyl ether: acetic acid (60:40:1, $\mathrm{vol} / \mathrm{vol} / \mathrm{vol}$ ) solvent. The separated spots were visualized by holding the plate in iodine vapor. The bands corresponding to 2-MAG were scrapped off and extracted 2 times with $5 \mathrm{ml}$ of diethyl ether. The extract was collected into a test tube and the solvents was removed under a stream of $\mathrm{N}_{2}$ gas. The amount of purified 2monoglyceride was estimated from the difference between the empty test tube weight and that with sample.

\section{Esterification reaction}

The purified 2-monoglycerides in the test tube were mixed with fatty acid methyl ester (3 times of 2-monoglyceride estimated weight) and dissolved in $3 \mathrm{ml}$ of hexane. Lipozyme RM IM enzyme (10\%) was added into the mixture to optimize the enzymatic esterification temperature $\left(50^{\circ} \mathrm{C}, 55^{\circ} \mathrm{C}\right.$ and $\left.60^{\circ} \mathrm{C}\right)$, time $(6,12$, 18, 24 hours) and lipase RM IM concentration $(2.5,5.0,7.5$, and 10.0) $\mathrm{wt} \%$ of total. The optimum condition for esterification was reported on our previous paper (Karouw et al., 2012). All of the enzymatic esterification reactions were carried out in a waterbath shaker operating at 120 strokes/minute. At the end of the experimental reaction, lipase was separated from the mixture by centrifugation. Solvents in the supernatant containing the triglycerides was evaporated under nitrogen gas flux and the remaining sediment was used for further triglyceride composition analysis.

\section{Glicerides composition analysis}

This step consists of triglyceride separation, purification, preparation of fatty acid methyl esters, and fatty acid identification by gas chromatography (GC) as follows:

\section{Triglycerides separation}

The sediment obtained from esterification reaction was dissolved in chloroform $(0.1 \mathrm{~g}$ of sediment $/ \mathrm{ml}$ of chlorofom) and then $20 \mu \mathrm{l}$ of the solution was applied to TLC plates and developed in petroleum ether: diethyl ether: acetic acid (60:40:1, vol/vol/vol). Spots were then analyzed using Camag TLC-scanner. The relative percentage of monoglycerides (MG), diglycerides (DG), triglycerides (TG), and free fatty acids (FFA) were based on the total area of the spots.

\section{Triglycerides purification}

The bands were visualized by holding the plate in iodine vapor. The bands corresponding to TAG (having $\mathrm{Rf}$ corresponding to TAG standard) were scrapped off and extracted twice with diethyl ether. The solvents were removed under a stream of $\mathrm{N}_{2}$ gas flux. The fatty acid profile of the TAG were analyzed by GC.

\section{Preparation of fatty acid methyl esters}

Fatty acid methyl esters of isolated TAG were prepared by transesterification in the presence of methanol and potassium chloride. A solution of TAG-hexane 5\% was prepared by dissolving isolated TAG in hexane. Into the 6 $\mathrm{ml}$ of TAG-hexane solution $150 \mathrm{ml}$ of $2.0 \mathrm{~N}$ potassium hydroxide was added. The mixture was then homogenized for $5 \mathrm{~min}$ and centrifused for $5 \mathrm{~min}$ at $3000 \mathrm{rpm}$. The fatty acid methyl esters in supernatan layer were separated and the solvent was evaporated under nitrogen gas flux. The fatty acid methyl esters were then analyzed by GC.

\section{GC analysis}

A Shimadzu-GC-9AM equipped with CPSIL-88 column $(30 \mathrm{~m} \times 0,30 \mathrm{~mm}$ id) and flame 
ionization detector (FID) was utilized. The injector and detector temperatures were $230^{\circ} \mathrm{C}$, while column temperature was previously held at $120^{\circ} \mathrm{C}$, then programmed to $200^{\circ} \mathrm{C}$ at $8^{\circ} \mathrm{C} / \mathrm{min}$. Nitrogen was used as a gas carrier.

\section{Oxidative and hydrolysis stability}

Oxidative stability was conducted according to Maduko et al. (2008); and Akoh and Moussata (2001). The obtained HMF was filled into an open test tube and placed in laboratory oven at temperature of $60^{\circ} \mathrm{C}$. The sample was evaluated for its peroxide value during $0,24,48$ and 72 hours of storage. The analysis of peroxide value was based on the methods of Champman and McKay (1949), as cited in Adnan (1980).

Hydrolysis test was performed according to Akoh and Moussata (2001). The obtained HMF analog was filled into open test tube and placed in room temperature. The free fatty acid content was monitored during 0,2, 4, 6 and 8 days of storage. Free fatty acid analysis was done according to method of Marseno et al. (2008). Evaluation of free fatty acid content was done using standard curve of lauric acid, as this fatty acid was the major fatty acid in HMF analog.

\section{Results and discussion}

Effect of temperature reaction on fatty acid profile of HMF analog

The fatty acid profile of HMF analog synthesized at various temperature $(50,55$ and $60^{\circ} \mathrm{C}$ ) (Table 1) was similar to fatty acids profile of the mother's milk.

Palmitic acid was the major fatty acid in HMF analog (22.81-24.8\%). The palmitic acid content in HMF analog was almost same as in human milk about $21.0 \%$ (Innis et al., 1994); 21.8\% (Lien et al., 1997) and 22,6 (Yuhas et al., 2006). The resulted HMF analog contained high percentage of MCFAs (35.83-47.55\%).

The results of this study, therefore, suggest that the condition to synthesis HMF analog from fatty acids methyl ester and 2-monoglyceride using lipozyme RM IM as biocatalyst was at $50^{\circ} \mathrm{C}$. The optimum temperature of lipozyme
RM IM for interesterification reaction was obviously dependent on the substrate in use. The obtained HMF analog contained high palmitic at sn-2 position and high lauric at sn-1 and sn-3 position.

\section{Effect of reaction time on fatty acid profile of HMF analog}

Fatty acids profile of HMF analog synthesized on various reaction time as shown in Table 2.

The results showed that percentage of lauric acid slightly increased after 6 to 18 hours and decreased after 18 hours. During the first 6 to 18 hours the esterification reaction occurred, then after 18 hours reaction was dominated by hydrolysis reaction. The results indicated that lauric acid could be esterified successfully during the first 6 to 18 hours of reaction. HMF analog contained high percentage of palmitic acid (21.88-24.11\%), similarly to pamitic acid in mother milk (22.6\%) (Yuhas et al., 2006).

\section{Effect of enzyme concentration on fatty acids profile of HMF analog}

Fatty acid profile of HMF analog esterified at various of enzyme concentration was shown in Table 3. The resulted HMF analog contained high percentage of palmitic acid around 24.33$27.43 \%$, almost similar to palmitic acid content in HMF around $22.6 \%$ (Yuhas et al., 206). The MCFA content was 35.15-43.86\%, higher compared to human milk. Maduko et al. (2007) and Maduko et al. (2008) have synthesized HMF analog contained medium chain fatty acid $28.0 \%$ and $20.7 \%$, respectively.

According to the results, therefore, we consider that the condition to synthesize HMF analog from fatty acid methyl ester of coconut oil and palm stearin 2-monoglyceride catalyzed by lipozyme RM IM was at $50^{\circ} \mathrm{C}$ for $12 \mathrm{~h}$ and enzyme concentration $10.0 \%(\mathrm{w} / \mathrm{w})$. It contained $43.86 \%$ of medium chain fatty acid and palmitic acid $24.33 \%$ similar to fat of mother milk.

Fatty acid profile of HMF analog and sn-2 position

The HMF analog, resulted from interesterification process of 2-monoglyceride 
Table 1. Fatty acids profile of HMF analog at various temperature through esterification of palmitic 2-monoglyceride and high lauric fatty acid methyl ester by using R. miehei as biocatalyst

\begin{tabular}{lrrr}
\hline \multirow{2}{*}{ Fatty acids } & \multicolumn{3}{c}{$\%$ Fatty acid } \\
\cline { 2 - 4 } & \multicolumn{1}{c}{$50^{\circ} \mathrm{C}$} & \multicolumn{1}{c}{$55^{\circ} \mathrm{C}$} & \multicolumn{1}{c}{$\mathrm{C} \mathrm{C}$} \\
\hline $\mathrm{C} 10: 0$ & $7.59 \pm 0.31 \mathrm{a}$ & $2.91 \pm 0.83 \mathrm{~b}$ & $1.99 \pm 0.29 \mathrm{~b}$ \\
$\mathrm{C} 12: 0$ & $39.96 \pm 1.66 \mathrm{a}$ & $40.28 \pm 2.06 \mathrm{a}$ & $33.84 \pm 0.55 \mathrm{a}$ \\
$\mathrm{C} 14: 0$ & $10.29 \pm 0.44 \mathrm{~b}$ & $18.12 \pm 0.48 \mathrm{a}$ & $15.75 \pm 0.74 \mathrm{a}$ \\
$\mathrm{C} 16: 0$ & $24.88 \pm 2.59 \mathrm{a}$ & $24.18 \pm 0.52 \mathrm{a}$ & $22.81 \pm 0.85 \mathrm{a}$ \\
$\mathrm{C} 18: 0$ & $3.56 \pm 0.37 \mathrm{a}$ & $3.46 \pm 1.17 \mathrm{a}$ & $3.21 \pm 0.33 \mathrm{a}$ \\
$\mathrm{C} 18: 1$ & $12.04 \pm 0.50 \mathrm{a}$ & $8.89 \pm 1.17 \mathrm{a}$ & $17.58 \pm 1.68 \mathrm{a}$ \\
$\mathrm{C} 18: 2$ & $1.69 \pm 0.07 \mathrm{a}$ & $2.16 \pm 0.25 \mathrm{a}$ & $4.82 \pm 0.62 \mathrm{a}$ \\
\hline
\end{tabular}

Note: The reaction was conducted at ratio of 2-monoglyceride:fatty $(1: 3, \mathrm{w} / \mathrm{w})$; enzyme concentration $10.0 \%(\mathrm{w} / \mathrm{w})$ in shaker waterbath at 120 strokes $/ \mathrm{min}$ for $24 \mathrm{hrs}$.

Numbers followed by the same letter at the same column are not significant difference at $5 \%$ of DMRT.

Table 2. Fatty acid profile of HMF analog at various time reaction through esterification of palmitic 2-monoglyceride and high lauric fatty acid methyl ester by using R. miehei as biocatalyst

\begin{tabular}{crrrr}
\hline \multirow{2}{*}{ Fatty acid } & \multicolumn{4}{c}{ \% Fatty acid } \\
\cline { 2 - 5 } & \multicolumn{1}{c}{$6 \mathrm{~h}$} & \multicolumn{1}{c}{$12 \mathrm{~h}$} & \multicolumn{1}{c}{$18 \mathrm{~h}$} & \multicolumn{1}{c}{$\mathrm{h}$} \\
\hline $\mathrm{C} 10: 0$ & $3,00 \pm 1,46 \mathrm{a}$ & $3,48 \pm 2,14 \mathrm{a}$ & $2,22 \pm 1,18 \mathrm{a}$ & $5,82 \pm 0,41 \mathrm{a}$ \\
$\mathrm{C} 12: 0$ & $31,39 \pm 0,73 \mathrm{a}$ & $33,06 \pm 0,67 \mathrm{a}$ & $33,17 \pm 0,55 \mathrm{a}$ & $32,57 \pm 1,43 \mathrm{a}$ \\
$\mathrm{C} 14: 0$ & $19,54 \pm 0,01 \mathrm{a}$ & $20,39 \pm 0,38 \mathrm{a}$ & $20,32 \pm 0,13 \mathrm{a}$ & $19,42 \pm 1,22 \mathrm{a}$ \\
$\mathrm{C} 16: 0$ & $21,88 \pm 1,86 \mathrm{a}$ & $22,49 \pm 0,51 \mathrm{a}$ & $24,11 \pm 1,63 \mathrm{a}$ & $22,37 \pm 0,28 \mathrm{a}$ \\
$\mathrm{C} 18: 0$ & $4,74 \pm 1,36 \mathrm{a}$ & $4,11 \pm 0,56 \mathrm{a}$ & $3,68 \pm 0,06 \mathrm{a}$ & $3,33 \pm 0,16 \mathrm{a}$ \\
$\mathrm{C} 18: 1$ & $17,29 \pm 1,50 \mathrm{a}$ & $15,21 \pm 0,16 \mathrm{a}$ & $14,52 \pm 0,96 \mathrm{a}$ & $14,74 \pm 2,54 \mathrm{a}$ \\
$\mathrm{C} 18: 2$ & $2,16 \pm 0,20 \mathrm{a}$ & $1,26 \pm 0,16 \mathrm{a}$ & $1,98 \pm 0,09 \mathrm{a}$ & $1,75 \pm 0,63 \mathrm{a}$ \\
\hline
\end{tabular}

Note: See Table 1 for the reaction condition.

Numbers followed by the same letter at the same column are not significant difference at $5 \%$ of DMRT.

Table 3. Fatty acids profile of HMF analog at various enzyme concentration through esterification of palmitic 2-monoglyceride and high lauric fatty acid methyl ester by using $R$. miehei as biocatalyst

\begin{tabular}{crrrr}
\hline \multirow{2}{*}{ Fatty acid } & \multicolumn{4}{c}{$\%$ Fatty acid } \\
\cline { 2 - 5 } & \multicolumn{1}{c}{$2.5 \%$} & \multicolumn{1}{c}{$5.0 \%$} & \multicolumn{1}{c}{$7.5 \%$} & \multicolumn{1}{c}{$10.0 \%$} \\
\hline $\mathrm{C} 10: 0$ & $4.13 \pm 0.40 \mathrm{a}$ & $3.68 \pm 0.44 \mathrm{a}$ & $4.23 \pm 1.83 \mathrm{a}$ & $4.49 \pm 0.43 \mathrm{a}$ \\
$\mathrm{C} 12: 0$ & $31.02 \pm 2.81 \mathrm{~b}$ & $34.55 \pm 2.24 \mathrm{ab}$ & $36.48 \pm 0.65 \mathrm{a}$ & $39.37 \pm 0.92 \mathrm{a}$ \\
$\mathrm{C} 14: 0$ & $14.79 \pm 0.52 \mathrm{a}$ & $15.58 \pm 1.81 \mathrm{a}$ & $14.46 \pm 0.23 \mathrm{a}$ & $16.06 \pm 0.39 \mathrm{a}$ \\
$\mathrm{C} 16: 0$ & $27.43 \pm 0.92 \mathrm{a}$ & $26.73 \pm 1.89 \mathrm{a}$ & $26.74 \pm 0.69 \mathrm{a}$ & $24.33 \pm 1.59 \mathrm{a}$ \\
$\mathrm{C} 18: 0$ & $4.38 \pm 0.17 \mathrm{ab}$ & $3.78 \pm 0.11 \mathrm{ab}$ & $2.82 \pm 1.26 \mathrm{~b}$ & $5.37 \pm 0.69 \mathrm{a}$ \\
$\mathrm{C} 18: 1$ & $16.52 \pm 0.73 \mathrm{a}$ & $13.78 \pm 2.28 \mathrm{a}$ & $13.88 \pm 0.41 \mathrm{a}$ & $8,98 \pm 0.74 \mathrm{~b}$ \\
$\mathrm{C} 18: 2$ & $1.73 \pm 0.08 \mathrm{a}$ & $1.90 \pm 0.20 \mathrm{a}$ & $1.39 \pm 0.72 \mathrm{a}$ & $1.4 \pm 0.11 \mathrm{a}$ \\
\hline
\end{tabular}

Note: See Table 1 for the reaction condition.

Numbers followed by the same letter at the same column are not significant difference at $5 \%$ of DMRT. 
Table 4. Fatty acid profile of human milk

\begin{tabular}{crc}
\hline \multirow{2}{*}{ Fatty acid } & \multicolumn{2}{c}{ \% Fatty acid } \\
\cline { 2 - 3 } & \multicolumn{1}{c}{ Total } & Sn-2 position \\
\hline C10:0 $12: 0$ & $4.49 \pm 0.43$ & $5.43 \pm 0.87$ \\
C14:0 & $39.37 \pm 0.92$ & $27.35 \pm 4.99$ \\
C16:0 & $16.06 \pm 0.39$ & $12.41 \pm 189$ \\
C18:0 & $24.33 \pm 1.59$ & $39.71 \pm 1.67$ \\
C18:1 & $5.37 \pm 0.69$ & $3.24 \pm 0.65$ \\
C18:2 & $8.98 \pm 0.74$ & $10.49 \pm 1.13$ \\
\end{tabular}

Note: Sinthesized by esterification of monoglyceride and FAME with lipozyme RM IM as biocatalyst $\left(\mathrm{MG} / \mathrm{FAME}=1: 3 \mathrm{w} / \mathrm{w}\right.$; incubation was at $50^{\circ} \mathrm{C}$ and $10 \%$ of enzyme for 12 hours in waterbath shaker 120 strokes/min).

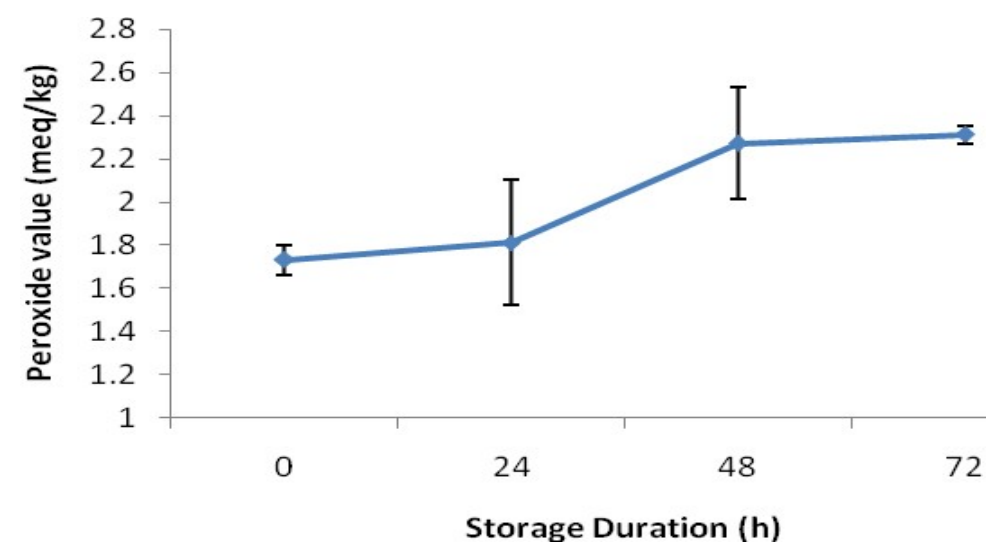

Figure 1. Pattern of peroxide value during at $60^{\circ} \mathrm{C}$

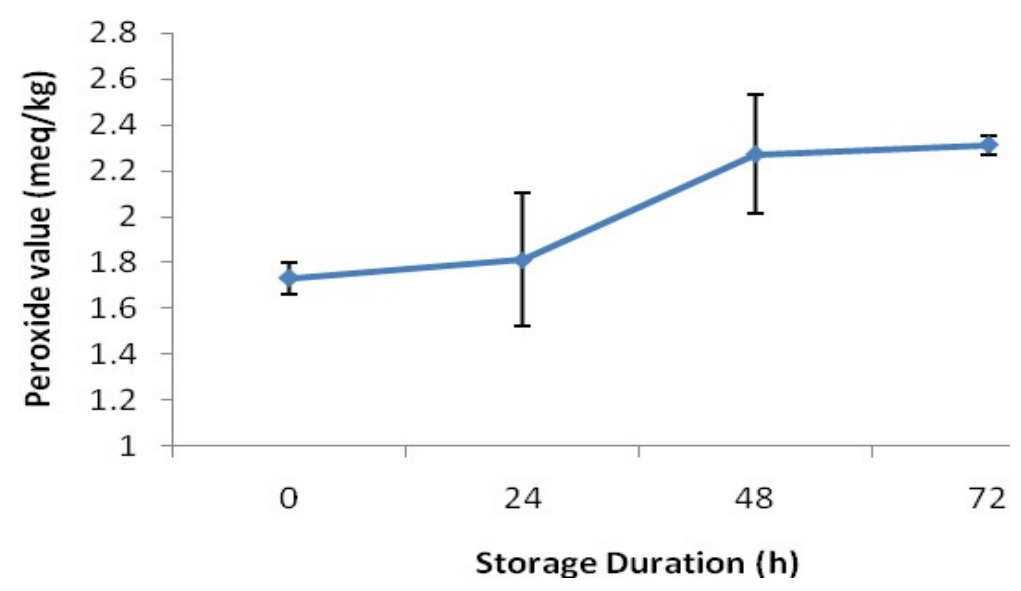

Figure 2. Pattern of free fatty acid of HMF analog during storage at room temperature 
derived from palm stearin and fatty acid methyl ester from coconut oil, was found to be rich of MCFAs. The fatty acid profiles of the HMF analog compared to fatty acid of human milk fat are presented in Table 4. The palmitic acid content, thought to be located in the sn-2 position of the HMF analog, is comparable to that of HMF. However, oleic acid, which also thought to be in the sn-2 position, was noticeably lower than that in the HMF. The MCFA (lauric acid from coconut oil) was successfully incorporated into the triglycerides. Ilyasoglu et al. (2010) reported that HMF analog synthesized from tripalmitin and Neobee (the mixture of MCFAs contained MCFAs of $23.4 \mathrm{~g} / 100 \mathrm{~g}$.

These results were similar to the earlier report by $\mathrm{Li}$ et al. (2009), who reported that HMF substitute synthesized from butterfat, rapeseed oil, and soybean oil using lipozyme RM IM, contained $24.5 \%$ of palmitic acid. The results also in line with Maduko et al. (2008), who interesterified coconut oil, soy bean oil, safflower oil, fish oil, and tripalmitin using lipozyme RM IM. They obtained human fat analog with palmitic acid around $23.0 \%$. Kuipers et al. (2012) and Yuhas et al. (2006) reported that palmitic acid content in milk fat of breast-feeding mothers in sub-Sahara Africa and the Philippines were $21.2-26.4 \%$ and $23.02 \%$, respectively.

\section{Oxidative stability of HMF analog}

The results showed that the peroxide value of resulted HMF analog has the peroxide value (PV) slightly increased during storage (Figure 1). The PV of HMF analog were $1.73 ; 1.81 ; 2.27$ dan $2.37 \mathrm{meq} / \mathrm{kg}$ at storage duration of $0,24,48$ and 72 hours, respectively. The PV was affected by the composition of fatty acid of HMF analog. Saturated fatty acids, having superior oxidative stability compared to unsaturated fatty acids, were the major fatty acid contained in the resulted HMF analog. Presumably, the peroxide was formed by oxidation of unsaturated fatty acids such as oleic and linolenic contained in HMF analog of 8.98 and $1.40 \%$, respectively. Almost of these two fatty acids esterified in sn-2 position of HMF analog. Oleic acid was more stable to oxidation when located in the sn-2 position of tryglyceride (Neff et al., 1994).

\section{Hydrolysis stability of HMF analog}

An elevation of storage duration increased the free fatty acids content of HMF analog (Figure 2). Before storage (0 day), the free fatty acid content of HMF analog was $0.43 \%$ and raised to $0.62,0.83,1.24$ and $1.37 \%$ during 2,4 , 6 and 8 days of storage duration, respectively. The results indicated that the hydrolysis deterioration occurred during storage of HMF analog. Hydrolysis deterioration of triglycerides was catalyzed by enzyme in the suitable water condition (Rossell, 1989; Gunstone, 1996).

The peroxide value and free fatty acid content during storage of HMF analog were almost similar to the previous studies. Therefore, we concluded that the resulted HMF analog was stable to oxidative and hydrolysis deterioration.

\section{Conclusion}

1. The resulted HMF analog had high percentage of palmitic acid in the sn- 2 . The palmitic acid content in the sn-2 position was around $39.71 \%$. The MCFA was esterified in the sn-1 and sn-3 positions and the main fatty acid constituent was lauric acid of $39.37 \%$.

2. The obtained HMF analog was stable to oxidative and hydrolysis deterioration which was indicated by the peroxide value and free fatty acid content during storage.

\section{Acknowledgments}

The authors gratefully acknowledge the financial support provided by the grant of KKP3T project by the Indonesian Agency for Agricultural Research and Development (2010). Furthermore, we would like to thank the Faculty of Agricultural Technology, Gadjah Mada University and the Indonesian Palmae Research Institute for providing facilities for this research.

\section{References}

Adnan, M. 1997. Teknik Kromatografi untuk Analisis Bahan Makanan. Penerbit Andi. Yogyakarta. 190 pp. 
Akoh, C.C. and Moussata, C.O. 2001. Characterization and oxidative stability of enzimatically produced fish and canola oil-based structured lipids. Journal of American Oil Chemists' Society 78(1): 2578.

Gunstone, F.D. 1996. Fatty Acids and Lipid Chemistry. Champman \& Hall, London. $252 \mathrm{pp}$.

Hamam, F. and Shahidi, F. 2006. Acidolysis reactions lead to esterification of endogenous tocopherols and compromised oxidative stability of modified oils. Journal of Agriculture Food Chemistry 54: 7319-7323.

Innis, S.M., Dyer, R. and Nelson, C.M. 1994. Evidence that palmitic acid is absorbed as $s n-2$ monoacylglycerol from human milk by breast-fed infants. Lipids 29(8): 541545.

Ilyasoglu, H., Gultekin-Ozguven, M. and Pzcelik, B. 2011. Production of human milk fat substitute with medium chain fatty acids by lipase-catalyzed acidolysis: optimization by responese surface methodology. LWT-Food Science and Technology. 44: 999-1004.

Jensen, R.G. 2002. Invited review: the composition of bovine milk lipids: January1995 to December 2000. Journal of Dairy Science 85: 295-350.

Karouw, S., Suparmo, Hastuti, P. and Utami, T. 2013. Hidrolisis Enzimatis Stearin Sawit menjadi Monogliserida oleh Lipase dari Rhizomucor miehei dan Pankreas. Agritech Jurnal Teknologi Pertanian 33(1): 53-59.

Kuipers, R.S., Luxwolda, M.F., Dijck-Brouwer, D.A.J. and Muskiet, F.A.J. 2012. Fatty acid compositions of preterm and term colostrum, transitional and mature milks in a sub-Saharan population with high fish intakes. Prostaglandins, Leukotrienes and Essential Fatty Acids. 86: 201-207.

Li, Y., Mu, H., Andersen, J.E.T., Xu, X., Meyer, O. and Orngreen, A. 2009. New human milk fat substitutes from butterfat to improve fat absorption. Food Research International 43: 739-744.

Lien, E.L., Boyle, F.G., Yuhas, R., Tomarelli, R.M. and Quinlan, P. 1997. The effect of triglyceride positional distribution on fatty acid absorption in rats. Journal of Pediatric Gastroenterology \& Nutritions 25: 167-174.

Maduko, C.O., Akoh, C.C. dan Park, Y.W. 2007. Enzymatic interesterification of tripalmitin with vegetable oil blends for formulation of caprine milk infant formula analogs. Journal Dairy Sci. 90:594-601.

Maduko, C.O., Park, Y.W. and Akoh, C.C. 2008. Characterization and oxidative stability of structured lipid: infant milk fat analog. Journal of American Oil Chemists' Society 85: 197-204.

Marina, A.M., Che Man, Y.B. and Nazimah, S.A.H. 2009. Chemical properties of virgin coconut oil. Journal of American Oil Chemists' Society 86: 301-307.

Marseno, D.W., Indrati, R. and Ohta, Y. 1998. A simplified method for determination of free fatty acids for soluble and immobilized lipase assay. Indonesian Food Nutrition Progress. 5(2): 79-83.

Martin, D., Regiero, G. and Senorans, F.J. 2010. Oxidative stability of structured lipids. Europe Food Research Technology 231:635-653.

Neff, W.E., Mounts, T.L. Rinsch, W.M., Konishi, H. and El-Agaimy, M.A. 1994. Oxidative stability of purified canola oil triacylglycerols with altered fatty acid composition as affected by triacylglycerol composition and structure. Journal of the American Oil Chemists' Society 71 (10): 1101-1109.

Nielsen, N.S., Yang, T., Xu, X. and Jacobsen, C. 2006. Production and oxidative stability of a human milk fat substitute produce from lard by enzyme technology in a pilot packed-bed reactor. Food Chemistry 94: 53-60. 
Seriburi, V. and Akoh, C.C. 1998. Enzymatic interesterification of lard and high oleic sunflower oil with Candida antartica lipase to produce plastics fats. Journal of American Oil Chemists' Society 75(10): 1339-1345.

Yuhas, R., Pramuk, K. and Lien, E.L. 2006. Human milk composition from nine countries. Lipids 41(9): 851-858.

Yuksel, A. and Yesilcubuk, N.S. 2012. Enzymatic production of human milk fat analog containing stearidonic acid and optimization of reactions by response surface methodology. Food Science an Technology. 46: 210-216. 